\title{
Butein induces apoptotic cell death of human cervical cancer cells
}

\author{
PEI-YU YANG ${ }^{1 *}$, DAN-NING HU ${ }^{2}$, YING-HSIEN KAO ${ }^{3}$, I-CHING LIN $^{4-6}$ and FU-SHING LIU ${ }^{7 *}$ \\ ${ }^{1}$ Department of Laboratory, Show Chwan Memorial Hospital, Changhua 50049, Taiwan R.O.C.; ${ }^{2}$ Tissue Culture Center, \\ New York Eye and Ear Infirmary of Mount Sinai, New York, NY 10003, USA; ${ }^{3}$ Department of Medical Research, \\ E-Da Hospital, Kaohsiung 82445; ${ }^{4}$ Department of Family Medicine, Changhua Christian Hospital, Changhua 50006; \\ ${ }^{5}$ Faculty of Medicine, Kaohsiung Medical University, Kaohsiung 80708; ${ }^{6}$ Faculty of Medicine, \\ Chung Shan Medical University, Taichung 40201; ${ }^{7}$ Department of Obstetrics and Gynecology, \\ Show Chwan Memorial Hospital, Changhua 50049, Taiwan R.O.C.
}

Received December 21, 2017; Accepted August 31, 2018

DOI: $10.3892 / \mathrm{ol} .2018 .9426$

\begin{abstract}
Butein is a chalcone, a flavonoid that is widely biosynthesized in plants. Butein has been identified to possess varied pharmacological activity and is extractable from traditional Chinese medicinal herbs, therefore applicable for disease treatment. Recently, in vitro and in vivo studies have shown that butein may induce apoptotic cell death in various human cancer cells. In this study we investigated the apoptotic effect of butein and the underlying mechanisms in human cervical cancer cells. Two cell lines, C-33A and SiHa cells, were treated with butein at different dosages for different durations. The effect of butein on cell viability was assessed by MTT assay, which revealed that butein exerted cytotoxicity in both cervical cancer cells in a dose- and time-dependent fashion. Apoptotic pathway-related factors in the butein-treated cervical cancer cells were then examined. JC-1 flow cytometry, cytochrome $c$
\end{abstract}

Correspondence to: Professor Fu-Shing Liu, Department of Obstetrics and Gynecology, Show Chwan Memorial Hospital, 542, Section 1 Chung-Shan Road, Changhua 50049, Taiwan R.O.C. E-mail: fsliufsliu@yahoo.com.tw

Mrs. Pei-Yu Yang, Department of Laboratory, Show Chwan Memorial Hospital, 542, Section 1 Chung-Shan Road, Changhua 50049, Taiwan R.O.C.

E-mail: peyyuh2900@gmail.com

${ }^{*}$ Contributed equally

Abbreviations: HPV, human papillomavirus; DMEM, Dulbecco's modified Eagle's medium; FBS, fetal bovine serum; DMSO, dimethyl sulfoxide; PBS, phosphate buffered saline; MTT, 3-(4,5-dimethylthiazol-2-yl)-2,5-iphenyltetrazolium bromide; PARP, poly (ADP-ribose) polymerase; IAP, inhibitors of apoptosis protein; XIAP, X-linked inhibitor of apoptosis protein; cIAP, cellular inhibitor of apoptosis protein; MTP, mitochondrial transmembrane potential; SDS, sodium dodecyl sulfate

Key words: butein, cervical cancer, cytotoxicity, apoptosis, inhibitor of apoptosis proteins assay, and caspase activity assays demonstrated that butein disturbed mitochondrial transmembrane potential, and increased cytosolic cytochrome $c$ levels and caspase activities in both cervical cancer cells. Western blot analysis revealed that butein downregulated anti-apoptotic protein Bcl-xL and led to proteolytic cleavage of poly (ADP-ribose) polymerase. In addition, butein decreased expressions of the inhibitor of apoptosis (IAP) proteins, including X-linked IAP, survivin, and cellular IAP-1. The findings of this study suggest that butein can decrease cervical cancer cell viability via a pro-apoptotic effect, which involves inhibition of the IAP proteins and activation of both extrinsic and intrinsic pro-apoptotic pathways. Therefore, butein may be applicable for cervical cancer treatment.

\section{Introduction}

Although the incidence of cervical cancer has decreased in developed countries due to the wide spread use of pap smear screening and the launch of HPV vaccinations, it is still the second most commonly diagnosed cancer and the third leading cause of cancer death among women of less developed countries. Epidemiological study estimated that there were 527,600 new cases and 265,700 deaths worldwide in 2012 (1). The major treatment strategy for cervical cancer at an early stage of disease is radical surgery. Radiation therapy is often used when patients are diagnosed at advanced stages or under unresectable conditions. Chemotherapy is usually used concurrently with radiation and inevitably regarded as an adjuvant therapy modality (2).

New therapeutic strategies for cervical cancer are currently being investigated. Among them, target therapy, particularly the anti-vascular endothelial growth factors agents, have been added to current chemotherapeutic regimens to treat advanced and recurrent cervical cancer with significant benefits being reported (3). In addition, the value of complementary and alternative medicines is also being investigated. For example, some herbal medicines have been reported to effectively induce apoptosis of cervical cancer cells and to have the potential for cancer treatment (4-7).

Butein (2',3,4,4'-tetrahydroxychalcone) is a plant polyphenol and an bioactive component extractable from the 
heartwood of Dalbergia odorifera, Caragana jubata, and Rhus verniciflua Stokes, and the stem bark of cashews (Semecarpus anacardium). These plant extracts have been reported to exert various pharmacological effects including anti-oxidant and anti-inflammatory activity, and they have long been used as a traditional herbal medicine in Asian countries (8-11) and claimed to have therapeutic potentials for chronic diseases, such as liver tuberculosis, obesity, diabetes and hypertension (12). Mechanistically, butein has been shown to be a specific protein tyrosine kinase inhibitor by repressing autophosphorylation level of epidermal growth factor receptor in HepG2 cells (13). In the context of butein-exhibited anti-cancer activity, previous in vitro pharmacological studies have shown that butein inhibits cell proliferation and induces apoptosis in numerous types of tumor cells, including lung (14), liver (15), pancreas (16), colon (17), bladder (18), prostate (19), breast (16), melanoma tumors (20), as well as ovarian (21) and cervical cancers (22). Moreover, butein is found to suppress migration and invasion of bladder (14), breast, and pancreatic cancer cells (15). In vivo studies further confirm that butein is able to inhibit the growth of prostate (19), breast and pancreatic tumors (16) in human tumor xenograft nude mouse models. In addition, butein also inhibits pulmonary metastasis of B16F10 melanoma cells in mice, mainly via decreasing angiogenic factor production (23).

The effect of butein on cervical carcinogenesis has been demonstrated by the studies using HPV18-containing HeLa cells. It is previously reported that butein suppresses proliferation and migration of HeLa cells, and inhibits growth of xenograft tumor cell in nude mouse model (22). Furthermore, butein combination treatment increases the sensitivity of HeLa cells to cisplatin in both in vitro and in vivo settings, while the underlying mechanism involves inhibition of AKT and MAPK pathways (24). Despite previous studies demonstrating involvement of apoptosis regulators in butein-induced cell death of cervical cancer cells, little is known about whether it also modulates the expression of inhibitor of apoptosis (IAP) proteins. The aim of this study was to examine its inhibitory ability on the growth of two human cervical cancer cell lines, C-33A (HPV negative) and SiHa (HPV16 positive) cells. The effects of butein on cytotoxicity, pro-apoptotic caspase activation and expression changes of various apoptosis regulators were examined in these two cervical cancer cell lines.

\section{Materials and methods}

Reagents. Butein pure compound was purchased from Enzo Life Sciences (Farmingdale, NY, USA; cat no. ALX-350-246). Butein was stocked at $30 \mathrm{mM}$ in dimethylsulfoxide (DMSO) and stored at $-80^{\circ} \mathrm{C}$ until use. The concentrations of DMSO in solvent control and all butein-treated groups were equal to or $<1 \%$ and showed no notable effect on cell viability. Dulbecco's modified Eagle's medium (DMEM; cat no. 11995-065), fetal bovine serum (FBS; cat no. 10437-028) and gentamicin (cat no. 15750-060) were obtained from Gibco (Thermo Fisher Scientific, Inc., Waltham, MA, USA). Primary antibodies against the Bcl-2 family proteins [Bax (1:1,000; cat no. 5023); Bak (1:1,000; cat no. 12105); Bcl-xL (1:1,000; cat no. 2764)], cellular IAP 1 (cIAP-1; 1:1,000; cat no. 7065), x-linked IAP (XIAP; 1:1,000; cat no. 2045), survivin (1:1,000; cat no. 2808), poly (ADP-ribose) polymerase (PARP; 1:1,000; cat no. 9532) and actin (1:5,000; cat no. 3700) were purchased from Cell Signaling Technology Inc. (Danvers, MA, USA). Goat anti-rabbit and goat anti-mouse secondary antibodies were purchased from Cell Signaling Technology (1:2,000; cat no. 7074) and Perkin-Elmer (NEF822001EA; 1:2,000; Boston, MA, USA), respectively.

Cell lines and cell culture. Two human cervical cancer cell lines were examined in this study. The C-33A cell line was obtained from the National Health Research Institute Cell Bank (Hsinchu, Taiwan), and the SiHa cell line was obtained from the American Type Culture Collection (Manassas, VA, USA). Both cell lines were cultured in DMEM medium supplemented with $10 \% \mathrm{FBS}$ and gentamicin $(50 \mu \mathrm{g} / \mathrm{ml})$. Both cell lines were maintained in a standard cell culture incubator at $37^{\circ} \mathrm{C}$ and in a humidified $95 \%$ air $/ 5 \% \quad \mathrm{CO}_{2}$ atmosphere.

3-(4,5-Dimethylthiazol-2-yl)-2,5-iphenyltetrazolium bromide) (MTT) cytotoxicity assay. Cervical cancer cells were trypsinized and seeded onto a 96-well plate at 5,000 cells per well for 24-h incubation. The cells were then exposed to butein at various concentrations $(0,10,30,100$ and $300 \mu \mathrm{M})$ for different incubation periods $(24,48$, and $72 \mathrm{~h})$. Cells that were not treated with butein were used as controls. After a volume of $50 \mu \mathrm{l}$ of $1 \mathrm{mg} / \mathrm{ml} \mathrm{MTT} \mathrm{solution} \mathrm{(cat} \mathrm{no.} \mathrm{M5655)} \mathrm{was} \mathrm{added}$ and incubated for $4 \mathrm{~h}$ at $37^{\circ} \mathrm{C}$, the solution was removed and $100 \mu 1$ of DMSO (cat no. D4540; both Sigma-Aldrich; Merck KGaA, Darmstadt, Germany) was added to lyse the cells. The MTT-formazan product was read with a microplate reader (Labsystems, Helsinki, Finland) at $550 \mathrm{~nm}$. The cytotoxic effect at each concentration of butein was determined by calculating the $\mathrm{IC}_{50}$ value with the control group as $100 \%$. Each assay was performed in triplicate.

Mitochondrial transmembrane potential (MTP) assay. MTP assay was performed using BD $^{\mathrm{TM}}$ MitoScreen (JC-1), Flow Cytometry Mitochondrial Membrane Potential Detection kit (cat no. 551320; BD Biosciences, Franklin Lakes, NJ, USA) according to the manufacturer's instructions. The aggregation of fluorescent lipophilic cationic probe JC-1 in mitochondria is sensitive for MTP detection. C-33A and SiHa cells were seeded onto 6-cm dishes for $24 \mathrm{~h}$ and exposed to different concentrations of butein $(0,10,30$, and $100 \mu \mathrm{M})$ for another $24 \mathrm{~h}$. In brief, cells were harvested, washed, and re-suspended in PBS. The cells were then incubated with JC-1 working solution for $10 \mathrm{~min}$ at $37^{\circ} \mathrm{C}$. The cells were then washed with assay buffer and analyzed using Accuri C6 flow cytometer (Beckton Dickinson, Ann Arbor, MI, USA). The aggregated dye located in the unaffected mitochondria emitted red florescence, whereas in cells with damaged MTP, the monomeric dye remained in cytoplasm showed diffuse green fluorescence (25).

Caspase-3, -8, and -9 activity assay. The caspase activity was detected using caspase-3, -8 and -9 colorimetric assay kit (cat nos. BF3100, BF4100 and BF10100; R\&D Systems Inc., Minneapolis, MN, USA) according to the manufacturer's protocol. Briefly, C-33A and SiHa cells were treated with 
A
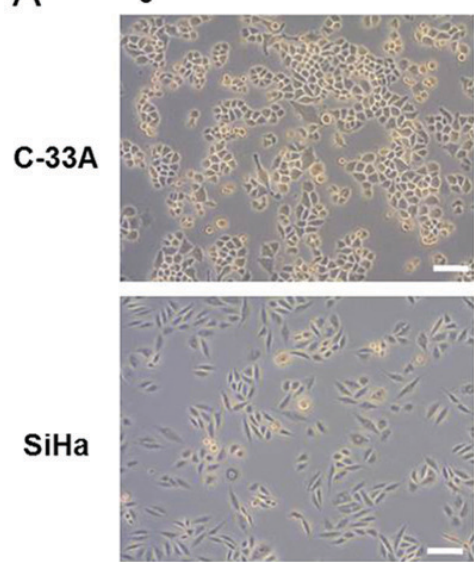

$30 \mu \mathrm{M}$ Butein

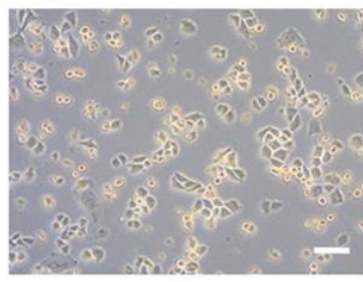

C-33A

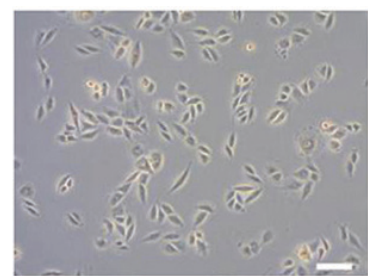

DMSO
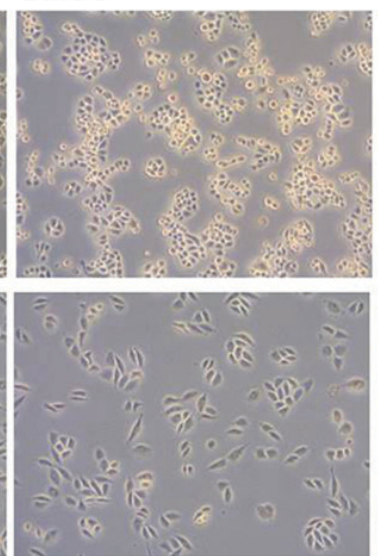

$100 \mu \mathrm{M}$ Butein

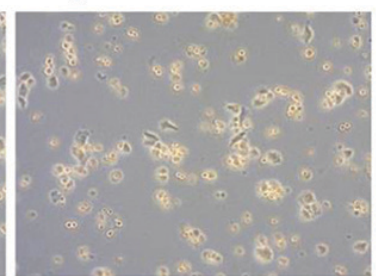

$10 \mu \mathrm{M}$ Butein
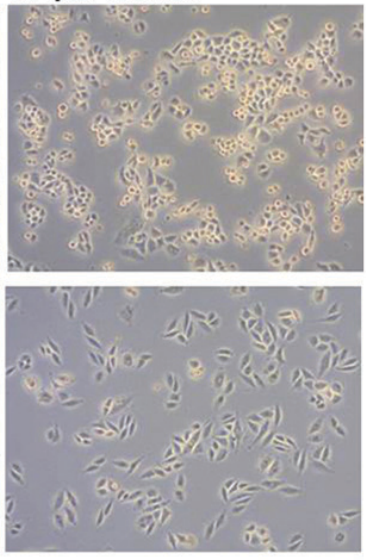

$300 \mu \mathrm{M}$ Butein
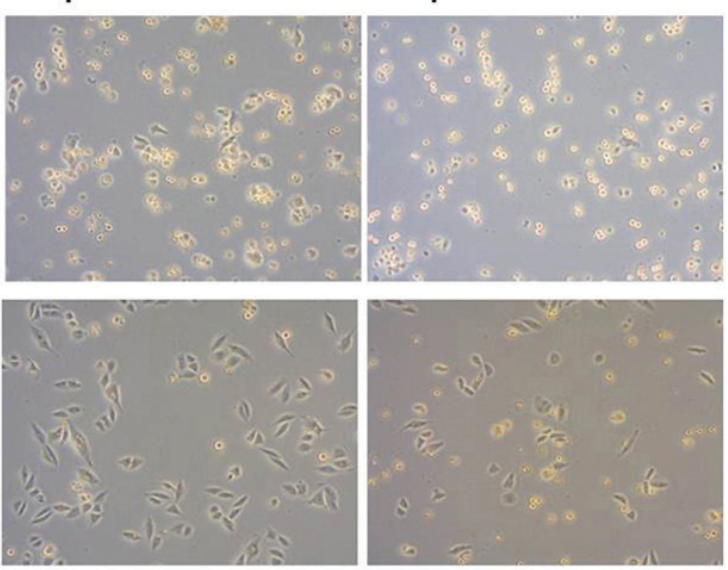
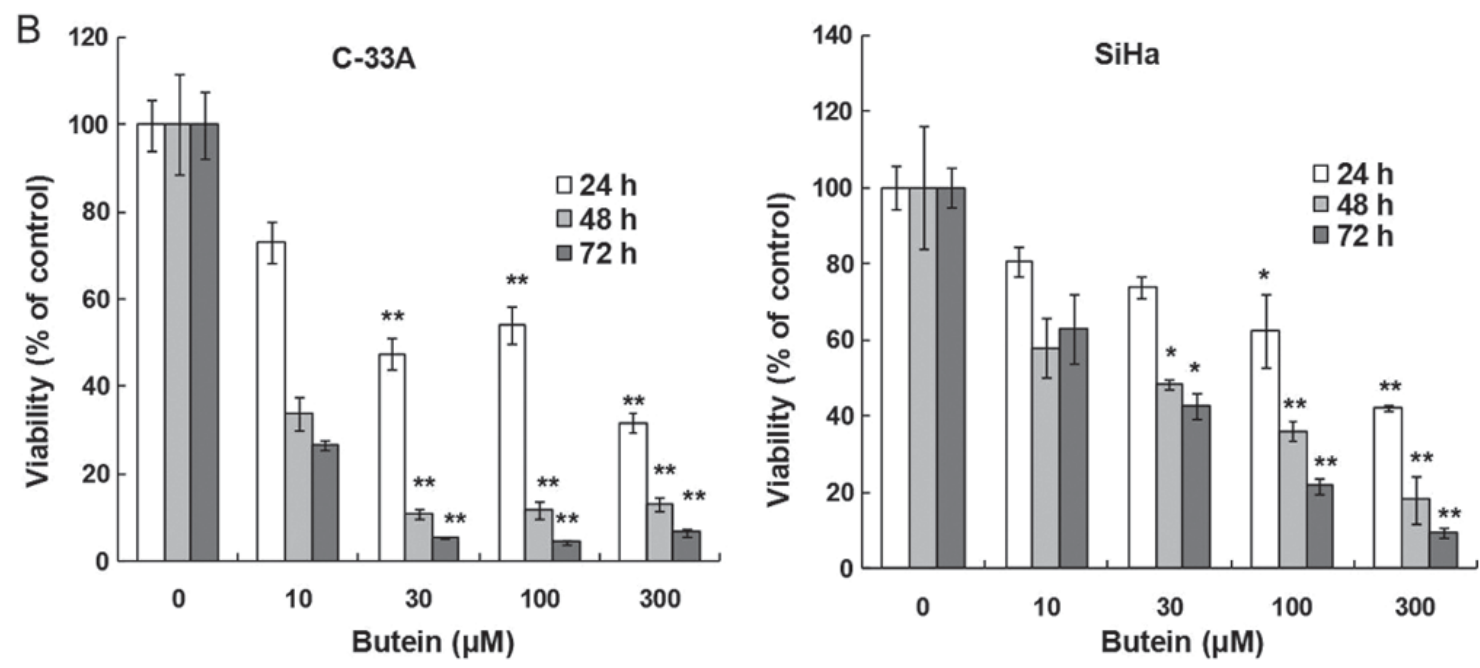

Figure 1. Cytotoxic effect of butein in C-33A and SiHa cervical cancer cells. (A) Phase-contrast photomicrograph of cervical cancer cells, C-33A and SiHa, treated with various concentrations of butein for $24 \mathrm{~h}$. (B) Both cells were treated with $0,10,30,100$ and $300 \mu \mathrm{M}$ of butein for 24,48 and $72 \mathrm{~h}$ and subjected to an MTT-based cytotoxicity assay. Scale bar, $100 \mu \mathrm{m}$. Data are presented as means \pm SD from three independent experiments. Asterisks indicate a significant difference compared with the control group ( $\left(\mathrm{P}<0.05\right.$ and $\left.{ }^{* *} \mathrm{P}<0.01\right)$. DMSO, dimethylsulfoxide; MTT, 3-(4,5-dimethylthiazol-2-yl)-2,5-iphenyltetrazolium bromide.

butein at various concentrations $(0,10,30$, and $100 \mu \mathrm{M})$ and cultured for $24 \mathrm{~h}$. The cells were then harvested, washed twice with PBS, and centrifuged at $150 \mathrm{~g}$ for $5 \mathrm{~min}$. Cell lysates were then incubated on ice for $10 \mathrm{~min}$, and centrifuged at $10,000 \mathrm{~g}$ for $1 \mathrm{~min}$. The lysates ( $100 \mu \mathrm{g}$ of total protein) were added to the reaction mixtures in a final volume of $50 \mu \mathrm{l}$, containing $5 \mu 1$ of colorimetric substrate peptides specific for either caspase-3 (DEVD-pNA), caspase-8 (IETD-pNA), or caspase-9
(LEHD-pNA). The mixtures were incubated at $37^{\circ} \mathrm{C}$ for an additional $2 \mathrm{~h}$. Finally, the absorbance at $405 \mathrm{~nm}$ was measured on a microplate reader, and the respective non-butein treated cells were used as controls. The results were shown as the induction fold over the values of controls.

Cytochrome c assay. A cytochrome $c$ ELISA kit (cat no. ALX-850-261; Enzo Life Sciences Inc.) was used to 
examine the release of cytochrome $c$ from mitochondria in butein treated cells. Briefly, cervical cancer cells were incubated with three concentrations of butein for $24 \mathrm{~h}$. The cells were then collected and washed with PBS, permeabilized with digitonin-containing buffer on ice for $5 \mathrm{~min}$. The cells were centrifuged, and the supernatants were collected and further diluted with the assay buffer. The samples were then placed on a cytochrome $c$ ELISA plate and allowed to incubate for $1 \mathrm{~h}$ at $500 \mathrm{rpm}$. The cytochrome $c$ conjugate was added and incubated for an additional $30 \mathrm{~min}$. The substrate solution for color development was added, and incubated at room temperature for $45 \mathrm{~min}$. After adding stop solution, the concentration of cytochrome $c$ in the cytosol was measured and read at $405 \mathrm{~nm}$ on a microplate reader.

Western blot analysis. C-33A and SiHa cells were seeded in a $10-\mathrm{cm}$ dish. After butein treatment, total cellular proteins were collected by lysing the cell pellets in RIPA buffer. A BCA protein assay kit (cat no. 71285; Novagen; Merck $\mathrm{KGaA}$ ) was used to determine the protein concentrations using bovine serum albumin as standards. Sodium dodecyl sulfate (SDS) polyacrylamide gel electrophoresis, electrotransferration, and immunodetection were performed as previously described (5). Equal amount of total protein $(50 \mu \mathrm{g})$ in each lane was initially loaded for gel resolution. An enhanced chemiluminescence detection system (cat no. NEL103001EA; Perkin Elmer Inc.) was used to detect immunoreactive signals, followed by densitometric analysis using Image J software (NIH, Bethesda, MD, USA). Signals for the housekeeping gene product $\beta$-actin were regarded internal controls. Three experiments were independently performed.

Statistical analysis. All quantitative data are shown as mean \pm SD. The statistical significance of difference was calculated using Mann-Whitney $U$ test when comparing between two groups or using the Kruskal-Wallis test followed by Dunn's post hoc test when comparing more than two groups. SPSS version 22 (IBM Corp., Armonk, NY, USA) was used for all statistical analyses. $\mathrm{P}<0.05$ was considered to indicate a statistically significant difference.

\section{Results}

Cytotoxic effect of butein in C-33A and SiHa cervical cancer cells. An MTT-based cytotoxicity assay was used to determine the cytotoxicity of butein in cervical cancer cells. The results revealed that butein reduced the viability of $\mathrm{C}-33 \mathrm{~A}$ and SiHa cells in a dose- and time-dependent manner. Compared to the cells that were not treated with butein, a progressive decrease in the cell viability of the C-33A and SiHa cells was observed with increasing dosage of butein (Fig. 1A and B). After treatment with butein at $30 \mu \mathrm{M}$ for $24 \mathrm{~h}$, the viability of C-33A cells decreased to $48 \%$ of the controls $(\mathrm{P}<0.05)$, and further decreased to $5.3 \%$ at $72 \mathrm{~h}(\mathrm{P}<0.01)$. The viability of SiHa cells also attenuated to 62 and $22 \%$ of the controls when exposed to butein at $100 \mu \mathrm{M}$ for 24 and $72 \mathrm{~h}$, respectively $(\mathrm{P}<0.05)$. The $\mathrm{IC}_{50}$ values of butein-treated $\mathrm{C}-33 \mathrm{~A}$ and $\mathrm{SiHa}$ cells are presented in Table $\mathrm{I}$. The difference in $\mathrm{IC}_{50}$ values between these two cell lines $(\mathrm{P}<0.05)$ suggested that butein
Table I. Cytotoxicity of butein in C-33A and SiHa cervical cancer cells with various treatment durations.

\begin{tabular}{lrrr}
\hline Cell line & $24 \mathrm{~h}(\mu \mathrm{M})$ & $48 \mathrm{~h}(\mu \mathrm{M})$ & $72 \mathrm{~h}(\mu \mathrm{M})$ \\
\hline C-33A & $79.88 \pm 7.45^{\mathrm{a}}$ & $9.95 \pm 3.38^{\mathrm{a}}$ & $8.30 \pm 1.32^{\mathrm{a}}$ \\
SiHa & $185.00 \pm 23.48$ & $30.54 \pm 2.57$ & $24.29 \pm 5.09$ \\
\hline
\end{tabular}

Butein-induced cytotoxicity was measured by MTT assay. ${ }^{\mathrm{a}} \mathrm{P}<0.05$ compared with the $\mathrm{IC}_{50}$ value of $\mathrm{SiHa}$ cells at the same treatment duration. MTT, 3-(4,5-dimethylthiazol-2-yl)-2,5-iphenyltetrazolium bromide.

induced higher cytotoxicity in C-33A cells than that in $\mathrm{SiHa}$ cells.

Damaging effect of butein on MTP. To measure the disrupting effect of butein on MTP in cervical cancer cells, the cells were stained with JC-1, which undergoes a potential-dependent aggregation in mitochondria and emits red fluorescence. On the contrary, the monomeric JC-1 dye remains in cytosol and emits green fluorescence, reflecting mitochondrial membrane depolarization. The representative results of flow cytometry shown in Fig. 2 clearly indicated that a dose-dependent increase in the percentage of green fluorescence-positive cells was noted in the butein-treated cervical cancer cells, from $6.5 \%$ in the controls to $50.4 \%$ in the $\mathrm{C}-33 \mathrm{~A}$ cells, and from $6.4 \%$ in the controls to $27.1 \%$ in the SiHa cells, respectively (Fig. $2 \mathrm{~A}$ and $\mathrm{B})(\mathrm{P}<0.05)$. The results indicated that butein significantly induced a loss of MTP in the cervical cancer cells.

Involvement of extrinsic and intrinsic pathways in butein-induced apoptosis. To clarify the pharmacologic action of butein on the apoptosis of cervical cancer cells, the regulators of extrinsic and intrinsic pro-apoptotic pathways were examined in butein-treated C-33A and SiHa cells. The caspase activity assay revealed that butein at doses equal to and higher than $30 \mu \mathrm{M}$ resulted in significant increases in the activities of caspase-3, -8 , and -9 in C-33A, while butein at concentrations up to $100 \mu \mathrm{M}$ prominently increased the activities of all these caspases in SiHa cells (Fig. 3). The results of cytochrome $c$ assay demonstrated that butein also dose-dependently increased cytosolic contents of cytochrome $c$ in both cervical cancer cell lines (Fig. 4). These findings suggested that extrinsic and intrinsic signaling pathways were both involved in the butein-induced apoptosis. Additionally, western blot analysis indicated that exposure of C-33A and $\mathrm{SiHa}$ cells to butein at $30 \mu \mathrm{M}$ or higher resulted in the proteolytic cleavage of PARP (Fig. 5), further supporting that butein induced apoptosis of both cervical cancer cells.

Modulation of butein on anti- and pro-apoptotic regulator expression. To assess whether Bcl-2 family proteins are affected in the butein-elicited apoptosis, both anti- and pro-apoptotic members of the Bcl-2 family members were measured in butein-treated $\mathrm{C}-33 \mathrm{~A}$ and $\mathrm{SiHa}$ cells. Western blot analysis clearly showed that butein induced a significant downregulation of the anti-apoptotic Bcl-xL protein at $30 \mu \mathrm{M}$ in $\mathrm{C}-33 \mathrm{~A}$ and $\mathrm{SiHa}$ cells, although butein at $100 \mu \mathrm{M}$ 

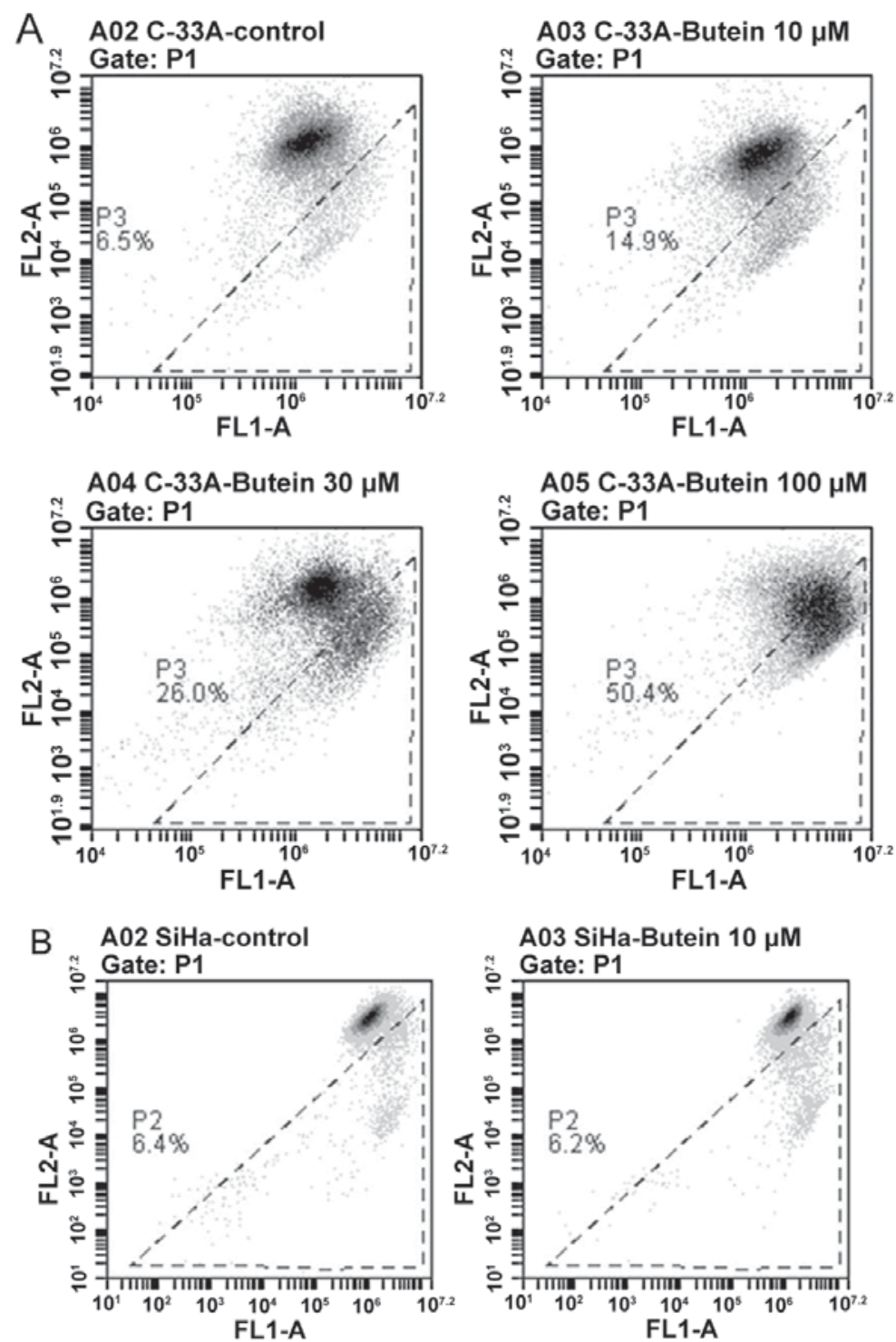

A04 SiHa-Butein $30 \mu \mathrm{M}$
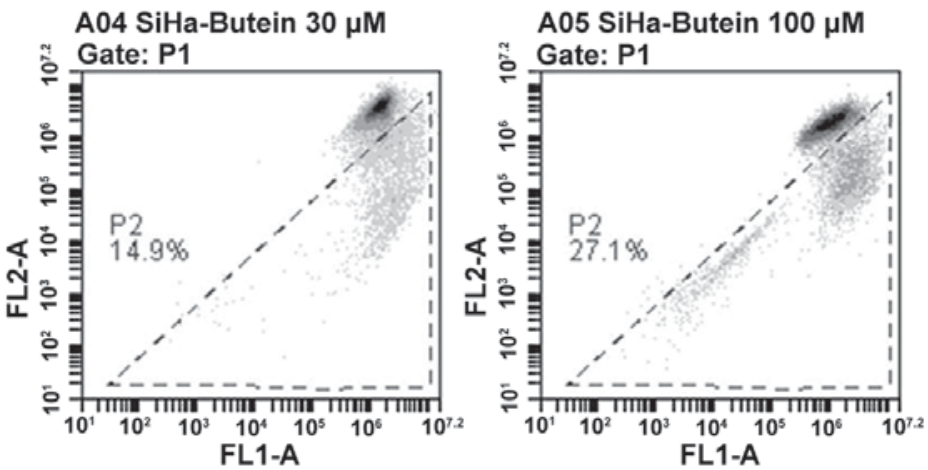

Figure 2. Butein dose-dependently depolarized mitochondrial transmembrane potentials in cervical cancer cells. Cervical cancer cells were treated with difference doses of butein for $24 \mathrm{~h}$ and subjected to JC-1 staining followed by flow cytometry. Note that significant increases in the percentage of green fluorescence-positive cells from (A) 6.5\% in the controls to 50.4\% in C-33A cells and (B) 27.1\% in SiHa cells, respectively (P<0.01). FL-1, green fluorescence; FL-2, red fluorescence. All experiments were repeated for at least three times.

did not significantly change the expressions of Bak and Bax pro-apoptotic proteins (Fig. 6) and anti-apoptotic Bcl-2 in both cell lines (data not shown).

Downregulation effect of butein on IAP proteins. Western blot analysis further showed that the IAP proteins in both C-33A and SiHa cells were downregulated after treatment with butein (Fig. 6). The expressions of XIAP and cIAP-1 in both $\mathrm{C}-33 \mathrm{~A}$ and $\mathrm{SiHa}$ cells significantly decreased when exposed to butein at $100 \mu \mathrm{M}(\mathrm{P}<0.01)$. Downregulation of survivin was also noted in $\mathrm{C}-33 \mathrm{~A}$ and $\mathrm{SiHa}$ cells with butein treatment at $100 \mu \mathrm{M}(\mathrm{P}<0.05)$. The cIAP-2 expression levels in both cells were not affected by butein treatment (data not shown). 

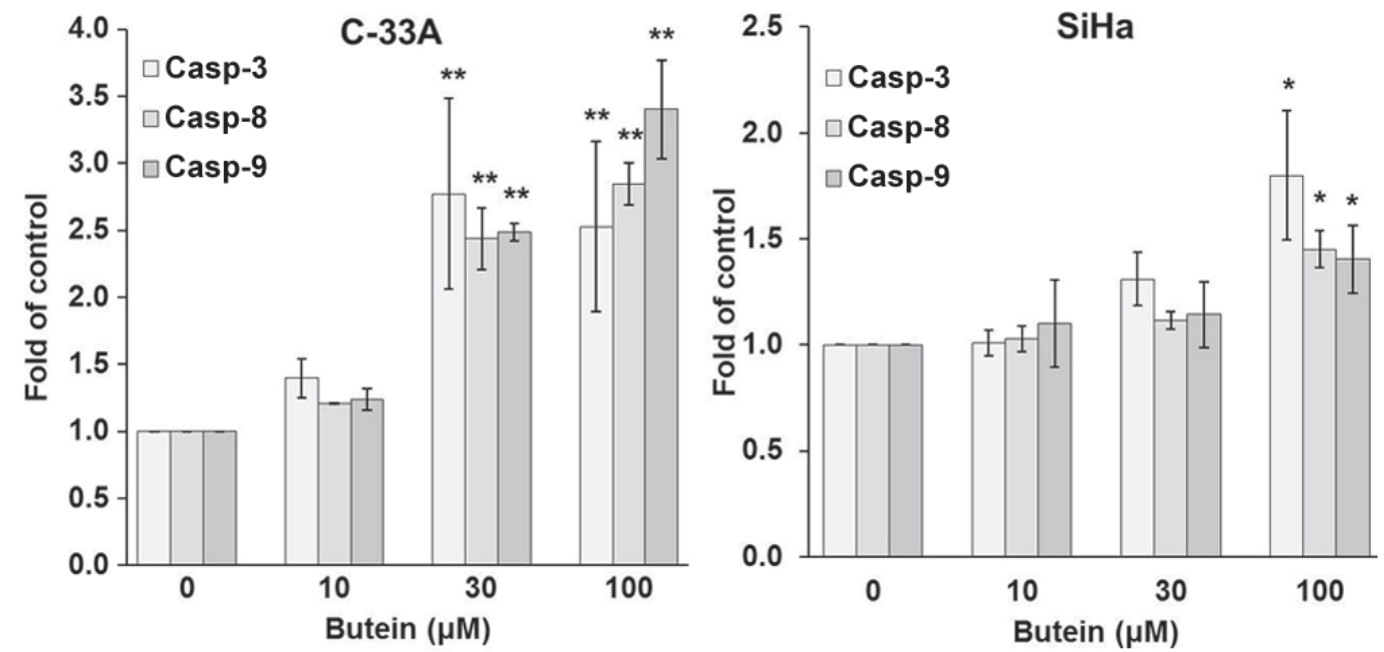

Figure 3. Butein significantly increased caspase activities in cervical cancer cells. Both C-33A and SiHa cervical cancer cells were treated with butein for $24 \mathrm{~h}$ and subjected to caspase activity assays, including caspase- $3,-8$, and -9 . Data are presented as means \pm SD from three independent experiments. "P<0.05 and ${ }^{* *} \mathrm{P}<0.01$, compared with dose zero control.
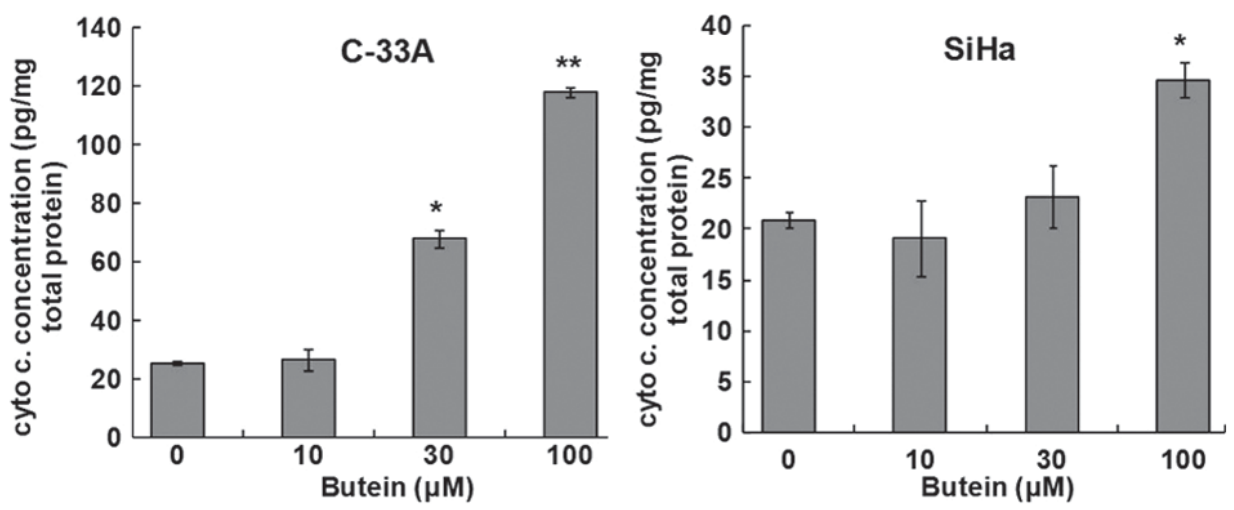

Figure 4. Butein significantly induced cytochrome $c$ release in cervical cancer cells. Both C-33A and SiHa cells were treated with butein at 10,30 and $100 \mu \mathrm{M}$ for $24 \mathrm{~h}$ and subjected to detection of cytosolic cytochrome $c$. Data are presented as means $\pm \mathrm{SD}$ from three independent experiments. ${ }^{*} \mathrm{P}<0.05$ and ${ }^{* *} \mathrm{P}<0.01$, compared with dose zero control.

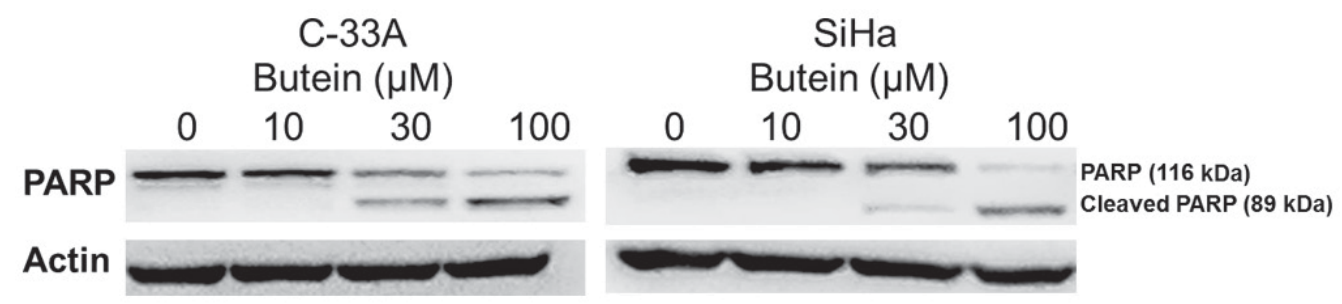

Figure 5. Butein induced cleavage of PARP in cervical cancer cells. Both C-33A and SiHa cells were treated with butein at different doses for $24 \mathrm{~h}$ and the protein lysates were subjected to western blotting detection. Representative images reveal the emergence of cleaved PARP peptides in both cells at $30 \mu \mathrm{M}$ and higher doses. PARP, poly (ADP-ribose) polymerase,

\section{Discussion}

Butein is a member of the chalcone family of open chain flavonoids that are extracted from medicinal plants and known to modulate protein tyrosin kinase activity. Butein has recently attracted attention due to its anticancer activity. Numerous in vitro and in vivo studies have shown that an increasing number of cancers could be inhibited by butein (15-21). These studies have identified that butein induces cancer cell death through induction of apoptosis. A clinical trial reported that the flavonoid Rhus verniciflua, which mainly contains butein, could decrease the tumor size of gastric cancer in an elderly patient and was well-tolerated (26).

In the present study, we examined whether butein has an anti-tumor effect on cervical cancer. Our results revealed that butein reduced cell viability in the two cervical cancer cells, C-33A and $\mathrm{SiHa}$, in a dose- and time-dependent manner. Consistent with our findings, the cytotoxicity of butein in 


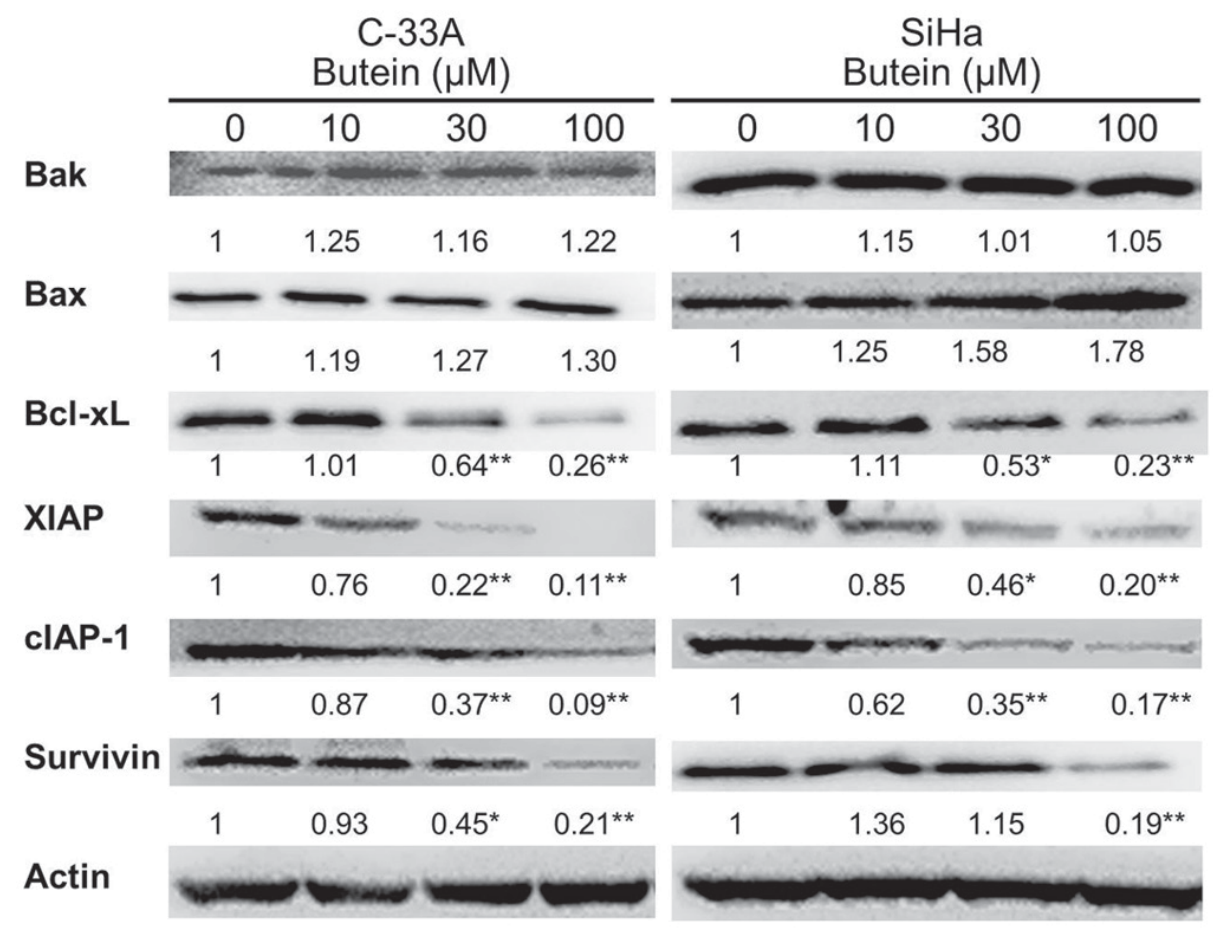

Figure 6. Butein treatment modulated expression of Bcl-2 and IAP family proteins in cervical cancer cells. Both C-33A and SiHa cells were treated with butein at different doses for $24 \mathrm{~h}$ and the protein lysates were subjected to western blotting detection. The intensity of each band was quantified by densitometric analysis using Image $\mathbf{J}$ software and was normalized to the respective internal reference ( $\beta$-Actin). The number below each representative blot is the mean of fold expression which was calculated from three independent experiments. ${ }^{*} \mathrm{P}<0.05$ and ${ }^{* *} \mathrm{P}<0.01$, compared with dose zero control. XIAP, $\mathrm{x}-\mathrm{linked} \mathrm{IAP}$; cIAP, cellular inhibitor of apoptosis protein.

HeLa cells has been previously demonstrated. Butein inhibited cervical cancer cell viability by the PI3K/AKT/mTOR and ERK/p38 MAPK pathway $(22,24)$. This study evaluated the in vitro chemosensitivity of two cervical cancer cell lines with difference HPV infection status after treatment with butein. The significantly different $\mathrm{IC}_{50}$ values between two tumor cells in response to butein suggest that butein is more sensitive in inhibiting HPV negative than that HPV16 positive cervical cancer cells.

The characteristic products of apoptosis, caspase-3 and the proteolytic cleavage of PARP, were increased in a dose-dependent manner in the butein-treated cervical cancer cells. Therefore, apoptosis appears to be an important mechanism by which butein exerts its anti-tumor effect on cervical cancer cells. Caspase activation cascade is a major signaling pathway involved in apoptotic cell death. There are two distinct routes to activate the caspase cascade, one from the cell surface (extrinsic pathway) and the other from mitochondria (intrinsic pathway). The extrinsic pathway involves activation of cell membrane receptors, adaptor proteins, and caspase- 8 , while activation of the intrinsic pathway from mitochondria requires Apaf-1, caspase-9 and cytosolic cytochrome $c$. Both routes can activate down-stream caspase-3 and lead to cell apoptosis (27). Consistent with the results observed in the butein-treated C-33A cells, Bai et al, reported that butein induced HeLa cells apoptosis through increasing caspase-3, -8 and -9 activities (22).

The Bcl-2 family proteins regulate apoptosis through the intrinsic mitochondrial pathway (28), and the ratio of pro-apoptotic to anti-apoptotic Bcl-2 proteins is known to critically regulate the apoptotic processes. In this study, butein decreased the expression of anti-apoptotic Bcl-xL protein in both $\mathrm{C}-33 \mathrm{~A}$ and $\mathrm{SiHa}$ cells, suggesting that butein may reduce the ratio of anti-apoptotic to pro-apoptotic $\mathrm{Bcl}-2$ proteins subsequently leading to mitochondrial change. In previous reports, butein decreased Bcl-2 anti-apoptotic and increased pro-apoptotic expression in various cancer cells (12). In addition, the results of MTP, cytochrome $c$, and caspase assays revealed that butein damaged MTP, increased the level of cytosolic cytochrome $c$, and increased the activity of caspase-9. These findings further support that butein induces apoptosis via the intrinsic pathway. The caspase assay revealed that the activity of caspase- 8 was increased, and therefore butien-induced apoptosis in the cervical cancer cells may also involve the extrinsic pathway.

IAP proteins are a family of proteins that play an important role in carcinogenesis because they can cause cancer cell proliferation and survival by inhibiting apoptotic induction and providing resistance to programmed cell death in cancer cells (29). Recently, therapeutic strategies have been designed to target the IAP proteins as a potential cancer treatment (30-33). There are eight members in human IAP proteins, of which XIAP is the most physiologically relevant direct inhibitor of caspase-3, -7, and -9 (34). Another two IAP protein members, cIAP-1 and cIAP-2, function as E3 ligases and promote RIP1 ubiquitination, which is associated with the pro-survival kinase TAK1 and facilitates cancer cell survival. Conversely, deubiquitinated RIP1 functions as a proapoptotic adaptor that binds to and activates caspase- 8 and thereby induces cancer cell apoptosis (35). Recent evidence indicates that higher expression of IAP proteins has been considered as one of characteristics of cancer stem-like cells and proposed as a therapeutic target through 
simultaneous activation of caspase-3/7 and autophagy flux (36). Survivin is involved in controlling cell division and inhibiting apoptosis (37). Upregulation of survivin has been reported to confer chemoresistance and contribute to tumor cell survival in various types of carcinomas, and therefore to be responsible for a poor prognosis (38). In this study, the downregulated expression of XIAP, cIAP-1, and survivin by butein strongly suggests that butein may induce apoptosis in cervical cancer cells through inhibiting the IAP protein expression and simultaneous activation of pro-apoptotic caspases. Intriguingly, targeting XIAP/caspase-7 complex has been found to effectively kill caspase-3-deficient malignancies, providing an opportunity to treat the resistant tumors with caspase-3 downregulation (39). Whether butein treatment also triggers caspase-7 activation via XIAP interaction in cervical cancer cells awaits further elucidation.

In addition to its pro-apoptotic activity, butein has long been known to modulate immune activity of the hosts with chronic diseases $(8,9,11)$. The molecular mechanism underlying the butein-induced anti-inflammatory effect has been identified to involve NF- $\mathrm{\kappa B}$ signaling activation in many types of cells (40). In the context of its antitumor activity, butein is reported to downregulate metastatic protease and angiogenic factor expression of prostate cancer cells (41) and chemokine receptor expression and function of breast and pancreatic tumor cells (16), mainly through inactivating NF- $\kappa \mathrm{B}$ signaling. Increasing evidence also supports the notion that anti-inflammatory drugs may also confer anti-neoplastic effect against uterine cervical cancer or HPV-dependent neoplasia (42). This raises the possibility that the combination strategy of using anti-inflammatory and conventional anti-tumor drugs may confer higher sensitivity to some types of tumors. In fact, butein has been known to sensitize cisplatin-induced cytotoxicity in HeLa cervical cancer cells (24) and TRAIL-induced hepatoma cell apoptosis (43). Further elucidation on the in vivo efficacy of butein and the combination therapy with conventional anti-tumor agent in cervical cancer treatment may warrant its translation to a clinical setting.

This in vitro study demonstrated that butein can decrease viability and induce apoptosis in cervical cancer cells at relatively low concentrations. The butein-induced apoptosis mechanistically involves activation of both extrinsic and intrinsic pathways, which may be regulated by inhibition of the IAP proteins. These findings suggest that butein may be a promising agent for the treatment of cervical cancer. Further in vivo and clinical studies are needed to verify its anticancer effect. In addition, the possible interactions of butein with other currently used anticancer drugs should be investigated.

\section{Acknowledgements}

Not applicable.

\section{Funding}

The present study was supported by a grant from Show Chwan Memorial Hospital, Taiwan (grant no. RA-16001) and part of this content was presented at 2016 IGCS biennial meeting, Lisbon, Portugal.

\section{Availability of data and materials}

The datasets used and/or analyzed during the current study are available from the corresponding author on reasonable request.

\section{Authors' contributions}

PYY, DNH and FSL designed the study. PYY and YHK performed the experiments. PYY, DNH and ICL analyzed the data. ICL performed the statistical analysis. All authors read and approved the manuscript.

\section{Ethics approval and consent to participate}

Not applicable.

\section{Patient consent for publication}

Not applicable.

\section{Competing interests}

The authors declare that they have no competing interests.

\section{References}

1. Torre LA, Bray F, Siegel RL, Ferlay J, Lortet-Tieulent J and Jemal A: Global cancer statistics, 2012. CA Cancer J Clin 65: 87-108, 2015.

2. Hacker NF and Vermorken JB: Cervical cancer. In: Berek and Hacker's Gynecologic Oncology. 5 edition. Berek JS, Hacker NF (eds). Lippincott Williams and Wilkins, Philadelphia, pp336-pp378, 2015.

3. Tewari KS, Sill MW, Long HJ III, Penson RT, Huang H, Ramondetta LM, Landrum LM, Oaknin A, Reid TJ, Leitao MM, et al: Improved survival with bevacizumab in advanced cervical cancer. N Engl J Med 370: 734-743, 2014.

4. Gao H, Lamusta J, Zhang WF, Salmonsen R, Liu Y, O'Connell E, Evans JE, Burstein S and Chen JJ: Tumor Cell Selective Cytotoxicity and Apoptosis Induction by an Herbal Preparation from Brucea javanica. N Am J Med Sci (Boston) 4: 62-66, 2011.

5. Takara K, Horibe S, Obata Y, Yoshikawa E, Ohnishi N and Yokoyama T: Effects of 19 herbal extracts on the sensitivity to paclitaxel or 5-fluorouracil in HeLa cells. Biol Pharm Bull 28: 138-142, 2005.

6. Yang PY, Hu DN and Liu FS: Cytotoxic effect and induction of apoptosis in human cervical cancer cells by Antrodia camphorata. Am J Chin Med 41: 1169-1180, 2013.

7. Zhou Y, Liu YE, Cao J, Zeng G, Shen C, Li Y, Zhou M, Chen Y, $\mathrm{Pu}$ W, Potters L and Shi YE: Vitexins, nature-derived lignan compounds, induce apoptosis and suppress tumor growth. Clin Cancer Res 15: 5161-5169, 2009.

8. Chan SC, Chang YS, Wang JP, Chen SC and Kuo SC: Three new flavonoids and antiallergic, anti-inflammatory constituents from the heartwood of Dalbergia odorifera. Planta Med 64: 153-158, 1998.

9. Jung CH, Kim JH, Hong MH, Seog HM, Oh SH, Lee PJ, Kim GJ, Kim HM, Um JY and Ko SG: Phenolic-rich fraction from Rhus verniciflua Stokes (RVS) suppress inflammatory response via NF-kappaB and JNK pathway in lipopolysaccharide-induced RAW 264.7 macrophages. J Ethnopharmacol 110: 490-497, 2007.

10. Lee JC, Lim KT and Jang YS: Identification of Rhus verniciflua Stokes compounds that exhibit free radical scavenging and anti-apoptotic properties. Biochim Biophys Acta 1570: 181-191, 2002.

11. Song Z, Shanmugam MK, Yu H and Sethi G: Butein and its role in chronic diseases. Adv Exp Med Biol 928: 419-433, 2016.

12. Padmavathi G, Roy NK, Bordoloi D, Arfuso F, Mishra S, Sethi G, Bishayee A and Kunnumakkara AB: Butein in health and disease: A comprehensive review. Phytomedicine 25: 118-127, 2017. 
13. Yang EB, Zhang K, Cheng LY and Mack P: Butein, a specific protein tyrosine kinase inhibitor. Biochem Biophys Res Commun 245: 435-438, 1998.

14. Li Y, Ma C, Qian M, Wen Z, Jing H and Qian D: Butein induces cell apoptosis and inhibition of cyclooxygenase-2 expression in A549 lung cancer cells. Mol Med Rep 9: 763-767, 2014.

15. Rajendran P, Ong TH, Chen L, Li F, Shanmugam MK, Vali S, Abbasi T, Kapoor S, Sharma A, Kumar AP, et al: Suppression of signal transducer and activator of transcription 3 activation by butein inhibits growth of human hepatocellular carcinoma in vivo. Clin Cancer Res 17: 1425-1439, 2011.

16. Chua AW, Hay HS, Rajendran P, Shanmugam MK, Li F, Bist P, Koay ES, Lim LH, Kumar AP and Sethi G: Butein downregulates chemokine receptor CXCR4 expression and function through suppression of NF- $\mathrm{\kappa B}$ activation in breast and pancreatic tumor cells. Biochem Pharmacol 80: 1553-1562, 2010.

17. Yit CC and Das NP: Cytotoxic effect of butein on human colon adenocarcinoma cell proliferation. Cancer Lett 82: 65-72, 1994.

18. Zhang L, Chen W and Li X: A novel anticancer effect of butein: Inhibition of invasion through the ERK1/2 and NF-kappa B signaling pathways in bladder cancer cells. FEBS Lett 582: 1821-1828, 2008.

19. Khan N, Adhami VM, Afaq F and Mukhtar H: Butein induces apoptosis and inhibits prostate tumor growth in vitro and in vivo. Antioxid Redox Signal 16: 1195-1204, 2012.

20. Cui Z, Song E, Hu DN, Chen M, Rosen R and McCormick SA Butein induces apoptosis in human uveal melanoma cells through mitochondrial apoptosis pathway. Curr Eye Res 37: 730-739, 2012.

21. Yang PY, Hu DN, Lin IC and Liu FS: Butein shows cytotoxic effects and induces apoptosis in human ovarian cancer cells. Am J Chin Med 43: 769-782, 2015.

22. Bai X, Ma Y and Zhang G: Butein suppresses cervical cancer growth through the PI3K/AKT/mTOR pathway. Oncol Rep 33: 3085-3092, 2015.

23. Lai YW, Wang SW, Chang CH, Liu SC, Chen YJ, Chi CW, Chiu LP, Chen SS, Chiu AW and Chung CH: Butein inhibits metastatic behavior in mouse melanoma cells through VEGF expression and translation-dependent signaling pathway regulation. BMC Complement Altern Med 15: 445, 2015

24. Zhang L, Yang X, Li X, Li C, Zhao L, Zhou Y and Hou H: Butein sensitizes HeLa cells to cisplatin through the AKT and ERK/p38 MAPK pathways by targeting FoxO3a. Int J Mol Med 36: 957-966, 2015.

25. Cossarizza A, Baccarani-Contri M, Kalashnikova G and Franceschi C: A new method for the cytofluorimetric analysis of mitochondrial membrane potential using the J-aggregate forming lipophilic cation 5,5',6,6'-tetrachloro-1,1',3,3'-tetraethylbenzimidazolcarbocyanine iodide (JC-1). Biochem Biophys Res Commun 197: 40-45, 1993

26. Lee SH, Choi WC, Kim KS, Park JW, Lee SH and Yoon SW: Shrinkage of gastric cancer in an elderly patient who received Rhus verniciflua Stokes extract. J Altern Complement Med 16: 497-500, 2010.

27. Cho SG and Choi EJ: Apoptotic signaling pathways: Caspases and stress-activated protein kinases. J Biochem Mol Biol 35: 24-27, 2002.

28. Frenzel A, Grespi F, Chmelewskij W and Villunger A: Bcl2 family proteins in carcinogenesis and the treatment of cancer. Apoptosis 14: 584-596, 2009.

29. Mace PD, Shirley S and Day CL: Assembling the building blocks: structure and function of inhibitor of apoptosis proteins. Cell Death Differ 17: 46-53, 2010.
30. de Almagro MC and Vucic D: The inhibitor of apoptosis (IAP) proteins are critical regulators of signaling pathways and targets for anti-cancer therapy. Exp Oncol 34: 200-211, 2012.

31. Fulda $\mathrm{S}$ and Vucic D: Targeting IAP proteins for therapeutic intervention in cancer. Nat Rev Drug Discov 11: 109-124, 2012.

32. Varfolomeev E and Vucic D: Inhibitor of apoptosis proteins: Fascinating biology leads to attractive tumor therapeutic targets. Future Oncol 7: 633-648, 2011.

33. Wang S: Design of small-molecule Smac mimetics as IAP antagonists. Curr Top Microbiol Immunol 348: 89-113, 2011.

34. Eckelman BP, Salvesen GS and Scott FL: Human inhibitor of apoptosis proteins: Why XIAP is the black sheep of the family. EMBO Rep 7: 988-994, 2006.

35. Bertrand MJ, Milutinovic S, Dickson KM, Ho WC, Boudreault A, Durkin J, Gillard JW, Jaquith JB, Morris SJ and Barker PA: cIAP1 and cIAP2 facilitate cancer cell survival by functioning as E3 ligases that promote RIP1 ubiquitination. Mol Cell 30: 689-700, 2008

36. Chen SM, Li YY, Tu CH, Salazar N, Tseng YY, Huang SF, Hsieh LL and Lui TN: Blockade of inhibitors of apoptosis proteins in combination with conventional chemotherapy leads to synergistic antitumor activity in medulloblastoma and cancer stem-like cells. PLoS One 11: e0161299, 2016.

37. Mita AC, Mita MM, Nawrocki ST and Giles FJ: Survivin: Key regulator of mitosis and apoptosis and novel target for cancer therapeutics. Clin Cancer Res 14: 5000-5005, 2008.

38. Zaffaroni N and Daidone MG: Survivin expression and resistance to anticancer treatments: Perspectives for new therapeutic interventions. Drug Resist Updat 5: 65-72, 2002.

39. Lin YF, Lai TC, Chang CK, Chen CL, Huang MS, Yang CJ, Liu HG, Dong JJ, Chou YA, Teng KH, et al: Targeting the XIAP/caspase-7 complex selectively kills caspase-3-deficient malignancies. J Clin Invest 123: 3861-3875, 2013.

40. Sung B, Cho SG, Liu M and Aggarwal BB: Butein, a tetrahydroxychalcone, suppresses cancer-induced osteoclastogenesis through inhibition of receptor activator of nuclear factor-kappaB ligand signaling. Int J Cancer 129: 2062-2072, 2011.

41. Moon DO, Choi YH, Moon SK, Kim WJ and Kim GY: Butein suppresses the expression of nuclear factor-kappa B-mediated matrix metalloproteinase-9 and vascular endothelial growth factor in prostate cancer cells. Toxicol In Vitro 24: 1927-1934, 2010.

42. Soriano-Hernandez AD, Madrigal-Perez D, Galvan-Salazar HR, Martinez-Fierro ML, Valdez-Velazquez LL, Espinoza-Gómez F, Vazquez-Vuelvas OF, Olmedo-Buenrostro BA, Guzman-Esquivel J, Rodriguez-Sanchez IP et al: Anti-inflammatory drugs and uterine cervical cancer cells: Antineoplastic effect of meclofenamic acid. Oncol Lett 10: 2574-2578, 2015.

43. Moon DO, Kim MO, Choi YH and Kim GY: Butein sensitizes human hepatoma cells to TRAIL-induced apoptosis via extracellular signal-regulated kinase/Sp1-dependent DR5 upregulation and NF-kappaB inactivation. Mol Cancer Ther 9: 1583-1595, 2010

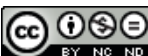

This work is licensed under a Creative Commons

Attribution-NonCommercial-NoDerivatives 4.0 International (CC BY-NC-ND 4.0) License. 